\title{
POTENCIAL POLUIDOR DE RESÍDUO SÓLIDO DA SAMARCO MINERAÇÃO: ESTUDO DE CASO DA BARRAGEM DE GERMANO ${ }^{1}$
}

\author{
José Maurício Machado Pires ${ }^{2}$, Jorge Carvalho de Lena ${ }^{3}$, Carlos Cardoso Machado ${ }^{4}$ e Reginaldo Sérgio Pereira ${ }^{5}$
}

\begin{abstract}
RESUMO - Foram estudadas amostras de resíduo sólido da Barragem de Germano, da Samarco Mineração S.A. Tal barragem localiza-se no município de Mariana-MG. Sua principal função é coletar os efluentes do tratamento do minério de ferro processado no Complexo de Germano. Este resíduo foi submetido a testes de classificação, de acordo com as Normas ABNT 10004, 10005, 10006 e 10007. Constatou-se que o resíduo é classe III (inerte) e que os testes mostraram a grande capacidade deste material na retenção de metais pesados e de cromo.
\end{abstract}

Palavras-chave: Testes de lixiviação, solubilização, classificação e resíduos sólidos industriais.

\section{POLLUTING POTENTIAL OF SAMARCO MINERAÇÃO S.A. SOLID WASTE: A GERMANO DAM CASE STUDY}

\begin{abstract}
Samples of solid waste from the Germano Dam of Samarco Mineração S.A were studied. This dam is located in the county of Mariana and it is mainly used to retain the waste resulting from the iron ore treatment at the Germano Plant. The waste was classified according to the ABNT Norms 10004, 10005, 10006 and 10007. as class III (inert) which was shown to be capable to retain heavy metals as well as chromium.
\end{abstract}

Key words: $\quad$ Leaching tests, solubilization, classification and industrial solid wastes.

\section{INTRODUÇÃO}

\subsection{O Problema e sua Importância}

Os termos poluição e contaminação se confundem no sentido comum da linguagem do dia-a-dia. No campo científico eles têm significados distintos. O termo contaminação é usado para designar uma substância química em uma amostra, sem evidência de que ela cause mal. Por outro lado, o termo poluição é usado em casos em que a presença de uma substância é danosa. Poluentes são, portanto, substâncias químicas que causam dano ao meio ambiente. Os tipos de poluição são os mais diversos, variando desde a simples poluição térmica até a inserção de metais pesados no ambiente (Crathorne et al., 1996).
A poluição industrial teve início com a manipulação dos materiais pelo homem primitivo. Talvez a origem dos problemas ambientais, particularmente a geração de resíduos, tenha ocorrido início séculos atrás, quando o homem começou a manusear metais como ferro, cobre e, posteriormente, chumbo. Apesar da vagarosa e incipiente atividade do homem nas diversas esferas, adotouse sempre a idéia de lançar de imediato qualquer resíduo no meio ambiente, e os receptores finais destes lançamentos acabavam sendo os rios, os lagos, os solos e a atmosfera.

As provas desse comportamento estão sendo estudadas atualmente, e apenas como exemplo pode-se citar que os teores de chumbo, cobre, zinco, estanho e

1 Recebido para publicação em 17.7.2002..

Aceito para publicação em 12.5.2003.

2 Mestre em Geologia pela Universidade Federal de Ouro Preto - UFOP, Ouro Preto-MG, Bolsista da CAPES/FAPEMIG;

${ }^{3}$ Professor do Departamento de Química da UFOP. ${ }^{4}$ Professor Titular do Departamento de Engenharia Florestal da Universidade Federal de Viçosa - UFV, 36571-000 Viçosa-MG; ${ }^{5}$ Doutorando do Departamento de Engenharia Florestal da UFV. 
mercúrio se encontravam acima do normal para aquela época, conforme se percebeu recentemente em grandes geleiras da Antártida, onde foram encontrados nutrientes derivados da atmosfera pantanosa, como também nos sedimentos aquáticos. Estes teores, que foram posteriormente datados, indicam que tais metais foram gerados e lançados na atmosfera. A História reforça esta descoberta. É sabido que os Romanos utilizavam grandes quantidades de chumbo, particularmente no encanamento para o transporte de água (Nriagu, 1996). Desconfia-se que os malefícios causados por este metal sejam uma das razões para o declínio daquele Império.

A poluição no mundo começou com o manuseio dos materiais pelo homem na Pré-História e se agravou com a Revolução Industrial, no século XVIII. Hoje, um dos grandes responsáveis pela poluição são os despejos industriais, que são originários de resfriamentos, lavagens, descargas, extrações, impregnações, tratamentos químicos, além de outros. No caso específico das mineradoras da região de Ouro Preto-MG, o rejeito é proveniente do tratamento do minério de ferro.

Os despejos que vêm do processamento da mineração são periodicamente tratados por processos que envolvem sedimentação simples e lançados em lagoas de sedimentação pelos dois tratamentos. Atualmente existem equipamentos muito eficientes nos tratamentos de resíduos e efluentes, alcançando, em determinados casos, $99 \%$ de eficiência, como observado em tratamento de gases e ar atmosférico.

No presente trabalho, realizado na região de Ouro Preto-MG, procurou-se avaliar o impacto causado pela ação exploratória de minério e do tratamento efetuado neste material. Um dos objetivos deste estudo foi a classificação deste material quanto à sua periculosidade.

\subsection{Processamento do Minério de Ferro Itabirítico}

Ominério de ferro proveniente da Mina de Germano (Samarco Mineração) sai por meio de correntes transportadoras, alimentando uma usina de britagem e peneiramento. Posteriormente, sofre um processo de flotação, que é um processo em que uma parte do minério se decanta e a outra parte fica suspensa. O processo de flotação utilizado é chamado de catiônica reversa porque utiliza um coletor catiônico (eteraminas ou eterdiaminas) e um depressor (o amido). Tanto o depressor como o coletor são compostos orgânicos que possuem uma cadeia polar ou hidrofílica, apresentando afinidade com a água,

R. Árvore, Viçosa-MG, v.27, n.3, p.393-397, 2003 e outra que não possui nenhuma afinidade com este solvente. A eteramina comumente usada como coletor adsorve o quartzo sobre sua superficie, tornando-o hidrofóbico e promovendo sua flotação. Este mineral é considerado a parte inútil do minério tratado, sendo coletado através de bolhas de ar e jogado fora. A flotação é chamada de reversa porque nesse processo, ao usar um coletor, retira-se o constituinte de menor interesse no produto final do processo produtivo.

O processo de depressão ocorre de modo a promover a decantação do mineral de interesse no minério, a hematita. Antes de fazer a depressão do minério, o depressor passa por um processo chamado de gelatinização, que consiste em adicionar uma solução de hidróxido de sódio até a solução atingir $\mathrm{pH}$ 10,5, o que é feito para quebrar as ligações entre os carbonos e oxigênios presentes na amilopectina, que é um açúcar presente no amido, constituído de moléculas de glicose. Com esta quebra expõemse os oxigênios deste açúcar, promovendo a adsorção da goethita em suas paredes superficiais.

Atualmente existe uma grande preocupação por parte das mineradoras que oferecem minério com teores de ferro superiores a $64 \%$. Assim, os níveis de impurezas como o fósforo devem estar abaixo de 0,1\% (Curi, 1991). Teores superiores a estes valores podem acarretar produção de aço quebradiço e com fraturas, o que torna este produto pouco atraente para sua utilização nas indústrias siderúrgicas. $\mathrm{O}$ fósforo pode estar presente no minério de ferro, ligando-se a minerais como goethita e bauxita, formando complexos de baixa solubilidade. Este é o motivo da preocupação com a presença de fósforo no minério a ser exportado ou vendido para as siderúrgicas.

\section{MATERIAL E MÉTODOS}

\subsection{Determinação da Composição Química}

A composição mineralógica do material, discutida anteriormente, indica que o material é formado, em sua maior parte, por goethita $(\mathrm{FeOOH})$, hematita $\left(\mathrm{Fe}_{2} \mathrm{O}_{3}\right)$ e quartzo $\left(\mathrm{SiO}_{2}\right)$. Foi encontrada também alguma caulinita $\left(\mathrm{A}_{2} \mathrm{Si}_{2} \mathrm{O}_{5}(\mathrm{OH})_{4}\right)$. Estes dados foram utilizados como uma tentativa de determinação quantitativa da composição mineralógica. Dadas às quantidades de cada componente, as determinações de ferro total, $\mathrm{SiO}_{2}$ e $\mathrm{H}_{2} \mathrm{O}$ foram realizadas por métodos clássicos como volumetria de oxirredução e gravimetria, enquanto o alumínio foi determinado por espectrofotometria de absorção atômica. 


\subsection{Determinação de Elementos-Traços}

As determinações de elementos-traços presentes no rejeito do processamento da Samarco tiveram a sua escolha baseada na necessidade da verificação de sua presença, conforme exigido pela Norma 10004 da ABNT.

\subsection{Classificação do Resíduo de Minério de Ferro}

A classificação do resíduo de minério de ferro foi feita de acordo com as Normas ABNT 10005 e 10006. Além da pura e simples classificação, realizou-se a avaliação do potencial poluidor do resíduo, através dos testes de lixiviação e solubilização, que podem ser interpretados como a quantidade de material poluidor que pode ser mobilizado para o sistema hídrico.

\section{RESULTADOS E DISCUSSÃO}

\subsection{Composição Química do Resíduo}

O Quadro 1 apresenta a composição química do resíduo proveniente do tratamento do minério de ferro. Nota-se que os teores de ferro estão em torno de $57,2 \%$, em média. Já os teores de $\mathrm{SiO}_{2}$ estão na casa dos $14 \%$, os de água de constituição em torno de $8 \%$ e os de $\mathrm{Al}$, de $1,3 \%$.

Quadro 1 - Teores dos constituintes maiores do resíduo do tratamento do minério da Samarco Mineração S.A. Table 1 - Contents of the major constituints of the iron or treatment waste of Samarco Mineração S.A.

\begin{tabular}{|l|c|c|c|c|}
\hline Amostra & $\mathrm{Fe}(\%)$ & $\mathrm{SiO}_{2}(\%)$ & $\mathrm{H}_{2} \mathrm{O}(\%)$ & $\mathrm{Al}(\%)$ \\
\hline PRO 1 & 56,6 & 14,2 & 7,8 & 1,2 \\
PRO2 & 57,6 & 14,2 & 7,9 & 1,3 \\
PRO3 & 57,1 & 14,1 & 7,7 & 1,5 \\
PRO4 & 57,1 & 14,1 & 7,5 & 1,1 \\
PRO5 & 58,3 & 14,2 & 7,6 & 1,3 \\
PRO6 & 56,8 & 14,3 & 7,8 & 1,3 \\
\hline Média & 57,2 & 14,1 & 7,7 & 1,3 \\
\hline
\end{tabular}

\subsection{Resultados dos Testes de Lixiviação e Solubilização}

Nos Quadros 3 e 4 estão os teores dos diversos elementos-traços obtidos nos testes de lixiviação $(\mathrm{Cr}, \mathrm{Cd}$ e $\mathrm{Pb}$ ) e solubilização $(\mathrm{Cr}, \mathrm{Cd}, \mathrm{Pb}, \mathrm{Mn}, \mathrm{Fe}$ e $\mathrm{Na})$. A simples inspeção e comparação dos valores obtidos com os valores tabelados na norma indicam que o resíduo pode ser classificado como classe III (inerte) (Rocca et al.,
1993). A classificação do resíduo é uma etapa importante deste trabalho. Nos Quadros 5 e 6 estão os limites máximos permissíveis no extrato obtido no teste de lixiviação e solubilização, segundo a Norma 10004 da ABNT (Associação Brasileira de Normas Técnicas).

Quadro 2 - Teores dos elementos-traços ( $\mu \mathrm{g} / \mathrm{g})$ no resíduo do tratamento do minério da Samarco Mineração S.A.

Table 2 - Contents of the trace-elements $(\mu g / g)$ of Samarco Mineração S.A. iron ore treatment waste

\begin{tabular}{|c|c|c|c|}
\hline Amostra & $\mathrm{Cr}$ & $\mathrm{Cd}$ & $\mathrm{Pb}$ \\
\hline PRO1 & 350 & $<0,2$ & $<2$ \\
PRO2 & 355 & $<0,2$ & $<2$ \\
PRO3 & 360 & $<0,2$ & $<2$ \\
PRO4 & 289 & $<0,2$ & $<2$ \\
PRO5 & 319 & $<0,2$ & $\mathrm{~K} 2$ \\
PRO6 & 297 & $<0,2$ & $<2$ \\
\hline Média & 328 & $<0,2$ & $<2$ \\
\hline
\end{tabular}

Quadro 3 - Teores de $\mathrm{Cd}, \mathrm{Cr}$ e $\mathrm{Pb}(\mu \mathrm{g} / \mathrm{ml})$ encontrados no líquido extrator do teste de lixiviação (Norma ABNT 10005) para o resíduo seco do processamento da Samarco Mineração S.A.

Table $3-C d, C r$ and $P b(\mu g / m l)$ contents found in the extracting liquid of the leaching test ( $A B N T$ Norm 10005) for the dry waste in Samarco Mineração S.A> processing

\begin{tabular}{|c|c|c|c|}
\hline Amostra & $\mathrm{Cd}$ & $\mathrm{Cr}$ & $\mathrm{Pb}$ \\
\hline PRO 1 & $<0,003$ & $<0,009$ & $<0,09$ \\
PRO 2 & $<0,003$ & $<0,009$ & $<0,09$ \\
PRO 3 & $<0,003$ & $<0,009$ & $<0,09$ \\
PRO 4 & $<0,003$ & $<0,009$ & $<0,09$ \\
PRO 5 & $<0,003$ & $<0,009$ & $<0,09$ \\
PRO 6 & $<0,003$ & $<0,009$ & $<0,09$ \\
\hline Média & $<0,003$ & $<0,009$ & $<0,09$ \\
\hline
\end{tabular}

Quadro 4 - Teores de $\mathrm{Cd}, \mathrm{Cr}, \mathrm{Pb}, \mathrm{Mn}, \mathrm{Fe}$ e $\mathrm{Na}(\mu \mathrm{g} / \mathrm{ml})$ encontrados no líquido extrator do teste de solubilização (Norma ABNT 10006) para o resíduo seco do processamento da Samarco Mineração S.A.

Table $4-C d, C r$ and $P b$ and $N a(\mu g / m l)$ contents found in the extracting liquid of the solubilization test ( $A B N T$ Norm 10006) for the dry waste in Samarco Mineração S.A. processing

\begin{tabular}{|c|c|c|c|c|c|c|}
\hline Amostra & $\mathrm{Cd}$ & $\mathrm{Cr}$ & $\mathrm{Pb}$ & $\mathrm{Mn}$ & $\mathrm{Fe}$ & $\mathrm{Na}$ \\
\hline PRO 1 & $<0,003$ & $<0,05$ & $<0,009$ & $<0,006$ & 0,069 & 107 \\
PRO 2 & $<0,003$ & $<0,05$ & $<0,009$ & $<0,006$ & 0,069 & 115 \\
PRO 3 & $<0,003$ & $<0,05$ & $<0,009$ & $<0,006$ & 0,069 & 116 \\
PRO 4 & $<0,003$ & $<0,05$ & $<0,009$ & $<0,006$ & 0,069 & 119 \\
PRO 5 & $<0,003$ & $<0,05$ & $<0,009$ & $<0,006$ & 0,069 & 118 \\
PRO 6 & $<0,003$ & $<0,05$ & $<0,009$ & $<0,006$ & 0,069 & 108 \\
\hline Média & $<0,003$ & $<0,05$ & $<0,009$ & $<0,006$ & 0,069 & 113,8 \\
\hline
\end{tabular}

R. Árvore, Viçosa-MG, v.27, n.3, p.393-397, 2003 
Quadro 5 - Limites máximos permissíveis no extrato obtido no teste de lixiviação segundo a Norma 10004 da ABNT (Associação Brasileira de Normas Técnicas)

Table 5 - Maximum allowable limits in the extract obtained from the leaching test, according to ABNT Norm 10004

\begin{tabular}{|l|c|}
\hline \multicolumn{1}{|c|}{ Poluente } & Limite máximo no lixiviado $(\mu \mathrm{g} / \mathrm{ml})$ \\
\hline Cádmio & 0,5 \\
Chumbo & 0,5 \\
Cromo Total & 5,0 \\
\hline
\end{tabular}

Quadro 6 - Limites máximos permissíveis no extrato obtido no teste de solubilização, segundo a Norma 10004 da ABNT (Associação Brasileira de Normas Técnicas)

Table 6 - Maximum allowable limits in the extract obtained from the leaching test, according to ABNT Norm 10004

\begin{tabular}{|l|c|}
\hline \multicolumn{1}{|c|}{ Poluente } & $\begin{array}{c}\text { Limite Máximo no Solubilizado } \\
(\mu \mathrm{g} / \mathrm{ml})\end{array}$ \\
\hline Cádmio & 0,005 \\
Chumbo & 0,05 \\
Cromo Total & 0,05 \\
Ferro & 0,3 \\
Manganês & 0,1 \\
Sódio & 200 \\
\hline
\end{tabular}

Os resultados dos testes de lixiviação e solubilização podem ser analisados em conjunto com os resultados de análises de elementos-traços presentes no resíduo, particularmente os de cromo.

\section{CONCLUSÕES}

Os resultados das análises de ferro podem ser utilizados para avaliar o teor de hematita no material. Está sendo levado em consideração que a hematita e a goethita são os dois únicos minerais que contêm ferro. No Quadro 1 observa-se que este elemento apresenta um teor médio de $57,2 \%$. Levando em consideração a fórmula mínima da goethita, constata-se que o seu teor de ferro é de $62,9 \%$. Sabendo que este mineral constitui $69,5 \%$ do material da empresa (o resíduo), chega-se a um teor de 40,0\% de ferro na amostra proveniente da goethita. Assim sendo, pode-se atribuir o restante à hematita, o que leva a um valor de $17,2 \%$ de ferro na amostra proveniente deste mineral. Este resultado corresponde a $24,6 \%$ de hematita no resíduo. O teor de quartzo pode também ser avaliado, combinando, agora, o teor de caulinita com os teores de $\mathrm{SiO}_{2}$ da análise química. Sabe-se que a caulinita tem um teor de 44,6\% de $\mathrm{SiO}_{2}$. O valor médio deste mineral no resíduo é de $6,7 \%$, o que conduz ao valor de $3,1 \%$ de $\mathrm{SiO}_{2}$, correspondente à caulinita. $\mathrm{O}$ valor médio de $\mathrm{SiO}_{2}$ na amostra é de $14,1 \%$. A diferença resulta na quantidade de quartzo - 11,0\%. Pode-se dizer assim, com alguma margem de segurança, que a composição mineralógica do material é

$\begin{array}{lll}\text { Goethita } & \mathrm{FeOOH} & 63,6 \% \\ \text { Hematita } & \mathrm{Fe}_{2} \mathrm{O}_{3} & 24,6 \% \\ \text { Quartzo } & \mathrm{SiO}_{2} & 11,0 \% \\ \text { Caulinita } & \mathrm{Al}_{2} \mathrm{Si}_{2} \mathrm{O}_{5}(\mathrm{OH})_{4} & 6,7 \%\end{array}$

Algumas observações devem ser feitas quanto a esses valores. A sua totalização difere de $100 \%$. O seu desvio-padrão é da ordem de $0,4 \%$, o que representa uma variação de quase $4 \%$ no teor de goethita, após os cálculos. Este erro também é propagado para o valor de hematita. Alguns autores (Gonii-Elizalde \& GarcíaClavel, 1988; Goss, 1987; Paterson \& Swafiield, 1980) já observaram que a goethita pode apresentar teores de água de até $14 \%$, muito maior que aquele previsto por sua fórmula mínima, o que também é uma fonte de variações nos cálculos.

Por outro lado, o teor de alumínio na amostra, calculado de acordo com o valor de caulinita, apresenta grande concordância. A caulinita no valor de $6,7 \%$ conduz a um teor de 1,4\% em Ai. A água de constituição também apresenta boa concordância.

Os resultados dos testes de lixiviação e solubilização podem ser analisados em conjunto com os resultados de análises de elementos-traços presentes no resíduo, particularmente os de cromo. $\mathrm{O}$ material beneficiado na usina é o itabirito, que contém um teor médio de cromo de $71 \mu \mathrm{g} / \mathrm{ml}$ (ppm) (Muller, 1991). Este elemento foi introduzido devido ao $\mathrm{pH}$ do meio estar acima do ponto de carga zero (PCZ) da goetita, o que faz com que este mineral apresente carga negativa, adsorvendo o $\mathrm{Cr}^{3+}$ sobre sua superfície cristalina, preconcentrando este elemento sobre esta e aumentando seu teor no material estudado. Os testes de lixiviação e solubilização do material apresentaram baixa concentração deste elemento no liquor, o que indica, em primeiro lugar, que este elemento não é disponibilizado para soluções aquosas e por extensão da barragem para o sistema hídrico. Alguns dão suporte a esta afirmativa. A água da barragem de Santarém apresenta um teor de $\mathrm{Cr}$ em torno de $8 \mathrm{ng} / \mathrm{ml}$ (ppb) (Matsumura, 
1999), enquanto a fração líquida da lama que é lançada para a barragem do Germano (que verte água para a barragem de Santarém) apresenta um teor de 600 ppb (Matsumura, 1999 a). Esta capacidade de retenção do cromo e de outros metais pesados se deve à presença de goetita no resíduo. A capacidade que este mineral apresenta para adsorver metais pesados tem despertado interesse de alguns autores. Segundo van Geen et al. (1994), a goetita possui grande capacidade de adsorção deste elemento. Tudo isto indica que o resíduo acumulado na Barragem de Germano tem capacidade de retenção de metais pesados e que esta barragem funciona na retenção de metais pesados e diminui a dispersão de poluentes.

\section{REFERÊNCIAS BIBLIOGRÁFICAS}

ASSOCIAÇÃO BRASILEIRA DE NORMAS TÉCNICAS ABNT. NBR -10004. Classificação de resíduos sólidos. Rio de Janeiro: 1987. 63 p.

ASSOCIAÇÃO BRASILEIRA DE NORMAS TÉCNICAS ABNT. NBR -10005. Lixiviação de resíduos sólidos. Rio de Janeiro: 1987. 7 p.

ASSOCIAÇÃO BRASILEIRA DE NORMAS TÉCNICAS ABNT. NBR -10006. Solubilização de resíduos sólidos. Rio de Janeiro: 1987. 7 p.

CRATHORNE, B.; DOBBS, A. J.; REES, Y. Chemical pollution of aquatic environment by priority pollutants and its control. In: HARRISON, R. M. (Ed.) Pollution causes, effects and control. 3.ed. London: The Royal Society of Chemistry, 1996. Part. 1.

CURI, A. Estudos para a redução do teor de fósforo em minérios de ferro. 1991. $130 \mathrm{f}$. Tese (Mestrado em Química Ambiental) - Universidade Federal de Minas Gerais, Belo Horizonte, 1991.
GOÑI-ELIZALDE \& GARCIA-CLAVEL, M. E. Thermal behavior in air of iron oxyhydroxides obtained from the method of homogeneous precipitation. Part I Goethite samples of varying crystallinity. Thermochimica Acta, v. 124 , p. $359-369,1988$.

GOSS C. J. The kinetics and reaction mechanism of the goethite transformation. Min. Magazine, v. 51, n. 1, p. 437-451. 1987.

MATSUMURA, M. S. Avaliação e estudo das emissões de metais pesados pela Barragem de Santarém (Samarco Mineração S. A.) no sistema hídrico da Região de Ouro Preto e Mariana. Um estudo da qualidade das águas. 1999. 113 f. Dissertação (Mestrado em Geologia) - Universidade Federal de Ouro Preto, Ouro Preto, 1999.

MATSUMURA, M. S. Dados não publicados. 1999a.

MULLER, G.; ROESER, H. Jazidas de ferro no Brasil Problemas de sua formação. Bases para o futuro. Brasília: CNPq, 1991. p. 249-259.

NRIAGU, J. O. A history of global metal pollution. Science, v. 272, p. 223-224, 1990.

PATERSON, E.; SWAFFIELD R. Influence of adsorbed anions on the dehydroxylation of synthetic goethite. Journal of Thermal Analysis, v. 18, p. 161-167, 1980.

ROCCA, A. A. C. et al. Resíduos sólidos industriais CETESB. São Paulo. 2.ed. 233 p. 1993.

VAN GEEN, A.; ROBERTSON, A. P.; LECKIE, J. O. Completion of carbonate species at the goethite surface: implications for adsorption of metal ions in natural waters. Geochimica et Cosmochimica Acta, v. 58, n. 9, p. 20732086, 1994. 